\title{
Doctor-Patient Relationship Epidemiology and its Implications on Public Health
}

\section{Turabian JL*}

Specialist in Family and Community Medicine Health Center Santa, Toledo, Spain

*Corresponding author: Jose Luis Turabian, Health Center, Santa Maria de Benquerencia, Toledo, Spain, Email: jturabianf@hotmail.com

\section{Review Article}

Volume 2 Issue 3

Received Date: November 09, 2018

Published Date: December 04, 2018

DOI: $10.23880 /$ eij-16000116

\section{Abstract}

Health surveys are commonly used to measure morbidity, but this type of instrument is not exempt from errors and difficulties. An alternative is the use of the data generated in the general practitioner's office, which can be especially useful. However, one aspect that has not been taken into account is the doctor-patient relationship in the consultation. The doctor-patient relationship is a professional, complex, multiple and heterogeneous social relationship. The models of doctor-patient relationship, depending on the interrelationship established between doctor and patient, imply different decision-making models (diagnostic and treatment). Since the symptoms are subjective evidences of health problems, and are expressed differently according to the context of the doctor-patient relationship, this variable limits the degree to which the physician obtains psychosocial information from the patient, and involves different diagnoses, and finally this has epidemiological consequences in morbidity data (prevalence and incidence of diseases and their distribution in the population). It is concluded that the processes of doctor-patient relationship play a mediating role between health resources and the outcomes of clinical encounters, and is an aspect of great importance in the treatment of patients, but also, in the epidemiological information. Due to the fact that doctor-patient relationship is a theoretically analyzed concept, but little studied, it would be important to try to characterize the distribution of the types of doctor-patient relationship that occur in the general medicine practice, in order to correct the epidemiological results or data of the diseases in the community.

Keywords: General Practice; Family Medicine; Physician-patient communication; Physician-Patient Relations; Framework; Decision Making; Diagnosis; Clinical Diagnosis; Uses of Epidemiology; Epidemiology; Prevalence; Morbidity; Medical Research; Public Health.

\section{Introduction}

\section{Basic Concepts of Epidemiology}

Epidemiology is the study of health phenomena that affect communities or human groups and the factors that influence these patterns, depending on time, place and people. It try to determine, over the years, whether a certain phenomenon or characteristic (for example, the illness) has increased or decreased, if its frequency in one geographical area is greater than in another, and if the people who have that certain phenomenon show characteristics different from those that do not

The epidemiologic knowledge of morbidity can only be identified within a population as "denominator: incidence (New cases or disease events, new symptoms, etc. in a defined population in a specified period of 
time), and prevalence (number of cases of the disease or condition in a population defined at a point in time; prevalence is an appropriate measure in only in that relatively stable conditions, and it is unsuitable for acute disorders) $[1,2]$.

Large population health surveys (that generally rely on respondent self-report) are commonly used to measure the morbidity. This is despite concerns about this technique: accuracy of self-reported health information, differences in measurement techniques sometime not compatible ones with other-, or with samples that distorted view of the size of the problem, low response rates which can lead to errors in estimating disease morbidity, etc. Further, larger surveys can be difficult to perform, unless large numbers of individuals are surveyed it is difficult to determine prevalence in small geographic areas, and although the cost of cross-sectional studies is relatively lower than other epidemiological designs -such as cohort studies-, their cost is not negligible, as they require some fieldwork, use questionnaires that are applied by interviewers, etc [3-6].

\section{Importance of the Epidemiological Contribution of General Practitioner}

The general practitioner / family doctor (GP) occupies a relevant place in the health care of the population, its role as health guardian, implies a performance primarily directed to the observation and action on any phenomenon or event that threatens against the welfare of the community. GP records are key sources for morbidity estimates, especially if all people are registered with a GP and this has a gatekeeper role in the health system. In this case, the population recorded in the general practices is representative of the entire population. In addition, the GP will also know the diagnoses of medical specialists and other health care providers [7].

In many health systems with similar organization (public salaried model, in Western European countries with public and state health centers, and whose GPs are paid through salary) these conditions are fulfilled: Dutch system, National Health Service of the United Kingdom, Portugal, Denmark, Sweden, etc. In these situations, in developed countries around two-thirds of any population consults in a General Medicine service at least once a year, and more than $80 \%$ contact once in 5 years. Collection of data in general medicine is cumulative and continuous: "the path of all patients" begins and ends with the family doctor $[8,9]$.

So, general practice is an important source of information on the occurrence and distribution of disease in the community [10]. Although it must be taken into account that if the data obtained in general doctor are from samples of consultations, a person likelihood of being sampled is dependent on visit frequency. Therefore, frequent attendants (such as patients who have more health problems) will be more likely to be sampled than infrequent attendants. It has been proposed the adjustment of the result according to the number of visits of the patients in the sample or includes patients only one time (for example, only the first visit) [3].

\section{The epidemiological importance of the diagnosis of disease in general medicine}

The incidence and prevalence of diseases in the practice of general medicine have an important effect on the probability of the disease and the sensitivity, specificity and predictive value of symptoms, signs and tests. In addition, the frequency of diseases in the community and the symptoms in each of the diseases, the risks to which the patient is subject, as well as the prior knowledge that the doctor has of it, are very important to elaborate the different diagnostic hypotheses.

The importance of epidemiological research at the GP level is often overlooked, not only in network work, but also individually, and the latter is undervalued. GPs have great opportunities to observe, analyze and investigate their patients, their problems and the diseases they present [11].

It must be borne in mind that the certainty of a diagnosis is not only important for the patient, but also for morbidity studies. In this regard, it has been reported that diagnoses of chronic diseases recorded in general practice are generally valid with a low number of false positive cases [12], and that there is concordance between health surveys and family medicine prevalence data are good for chronic conditions [10,13-16]. On the other hand, data from general medicine may have higher reliability at a local level, and thus can improve community health surveillance by identifying local variation of disease prevalence.

In this scenario, this article aims to reflect on the effects on clinical and epidemiological data that the introduction of the variable "doctor-patient relationship" has, and consequently its implications regarding public health.

\section{Discussion}

The Symptoms are Subjective and their Expression and Nuances Depend on the Context of the Communication and DoctorPatient Relationship

The symptoms are "any subjective evidence of a health problem as perceived by the patient." The 


\section{Epidemiology international journal}

symptoms are the result of a process of interpretation. Symptomatic experiences are integrated into a complex interaction between biological, psychological and social factors. And the expression of symptoms depends more on psychosocial than biological aspects. Consequently, there is a wide variety of interpretations and expressions of sensations, which are not equivalent to the expressions of the underlying disease $[17,18]$. Consequently, the symptoms are expressed or not, in one way or another, by the patient in the context of the doctor-patient interview, and can be received and understood by the doctor.

Even a study by image (which is theoretically the most "objective" there is) can lose its meaning if it is abstracted from the clinical context of the patient. An image in a test can be seen in multiple processes and analyzed without knowing the clinical picture of the patient can lead to a diagnostic error. Even the pathologist needs clinical data to make a diagnosis! The clinic must decide on the diagnosis. That is, the subjective decides the diagnosis; or in other words, contextualization makes this "subjectivity" is "objective" $[19,20]$.

Diagnosis is one of the fundamental tasks of physicians and the basis for effective therapy. But, the doctor-patient relationship is fundamental to obtain the information doctor needs in the diagnosis process. With a good doctor-patient relationship we managed to give tranquillity and security, as well as a better exposure of the symptoms by the patient and a greater cooperation in the physical examination. You have to bear in mind that anamnesis is the fundamental base for the diagnosis of the health problems of our patients: from 50 to $80 \%$ of the diagnoses are made by the interview. In addition, the physical examination should not be neutral, but guided by the anamnesis $[19,21,22]$.

\section{The epidemiological importance of doctor- patient relationship}

The doctor-patient relationship is a professional social relationship, and as such subject to avatars and the evolution of society itself. It is a complex, multiple and heterogeneous relationship that can not be defined in a unique way or generalize a only concept of relationship, but there are "many" doctor-patient relationships appropriate according to their contexts, which on the other hand can be changing, according to different moments or encounters. All this makes doctorpatient relationship also difficult to measure [23]. In the doctor-patient relationship, technical, human and social elements coexist, and it is a relationship that can be specific or extend for years [24].

In the attitudes of physicians during the doctorpatient relationship, many personal factors influence: their emotional and affective situation, their self- esteem, their confidence in their own professional preparation, their beliefs and conceptions, their personality, their individual and family history related with disease itself and with the medicine itself, the characteristics of the disease it faces, the difficulties in diagnosis and / or treatment, the stage of life through which it is going through, its social and economic situation, the degree of discomfort or welfare in the workplace [25].

With all that baggage of factors that influence him, the GP performs in the consultation with the patient, a work of "creation of contexts" through the relationships and communications established with the patients of the consultation. The creation of context is the result of implementing a series of doctor-patient relationship strategies to make services acceptable, relevant and accessible [26] [27-32]. The types of relational context or simply doctor-patient relationship could be classified into [33]: 1. A type of relationship is the "activepassive": patient participates very little in the relationship; 2 . Probably the type most frequently used is "guided cooperation": patient can receive guidance and he should cooperate in their treatment; 3. A type of relationship as a consumer increasingly frequent: patient becomes a "buyer" or "client", with specific demands of this situation, and doctors become "sellers."; 4. Finally, a relationship of "mutual participation" or "patient-centered": doctor discusses with the patient their management of the disease and the situations that create anxiety, and tries to provide ways to understand the patient's "experience of getting sick", considering it a fundamental part to reach the diagnosis and an adequate treatment. Regarding this type of relationship (Patient-centered care) it has been reported that it obtain better psychosocial information and doctor can connect with patients, so enhancing the physician's understanding of the patient's life situation, improving outcomes, ordering fewer unnecessary tests and referrals, reducing costs, improving the compliance, satisfaction, empowerment, and the memory of the information given by the doctor in the consultations [34-38].

Regarding the attitudes shown by GPs during the consultation, in studies based on patient communication, it is said that $80 \%$ of GPs "take into account the opinion of the patient" [25]. However, studies are missing that describe how the different types of doctor-patient relationship are distributed, which go only beyond intuitions.

Although the current tendency is to consider the relationship of "mutual participation" or "patientcentered" as a desirable situation, and in this way the shared decision, from the technical medical point of view, it is not always necessary to involve the patient in the relationship and decision. The elements to be 


\section{Epidemiology international journal}

considered to assess the need for involvement are: certainty or uncertainty regarding the course of action to be followed, and the low or high risk involved for the patient. Based on this, it will be advisable to use, as the case may be: 1 . An "active-passive" relationship where the patient, due to his pathology, participates very little in the relationship, and the decision may involve the transmission of simple information: 2. A "guided cooperation" relationship where the patient can receive guidance and cooperate in their treatment, and can include the informed consent; and 3. A "mutual participation" relationship where decision aid tools are used.

Thus, the doctor-patient relationship model is probably variable depending on the circumstances. For example, a unidirectional "active-passive" relationship may be appropriate where the patient, because of his pathology, participates very little in the relationship, and the doctor transmits the simple information to the patient, which can be framed in a specific relational context, as in the acute stages of predominantly biological diseases, where the decisions have as objective that the patient knows what the doctor has decided to do.

On other occasions, a relationship of "guided cooperation" may be relevant after the days of the acute condition, which pursues ties that guarantee the proper treatment, or a "Consumerist" relationship model where the transmission of information and decision may involve informed consent, which adjusts more to a "defensive" context, where the doctor has already made the decision and seeks the patient to assume responsibility if "foreseeable" problems arise

Finally, in other occasions there may be moments when the doctor-patient relationship be of "mutual participation" and include the tools of decision support, which are those that really are part of a participatory context (there is no decision made by the doctor) and have as objective that the patient acquires enough information to be able to take the decision, with the help of the doctor [39].

All these types of doctor-patient relationship can be right in their context, and they may occur over time in the same doctor-patient dyad, but each of them will possibly involve obtaining a different quantity and quality of clinical information, which, added to community level, will give rise to different epidemiological data and public health implications.

\section{Conclusion}

In short, the processes of doctor-patient relationship play a mediating role between health resources and the outcomes of clinical encounters. Doctor-patient relationship is a fundamental concept to be able to use the morbidity data of general medicine. The different possibilities of doctor-patient relations point in the direction in which in each of these relationship contexts, the information expressed by the patient and that obtained by the doctor will be different. The models of doctor-patient relationship, depending on the interrelationship established between doctor and patient, imply different decision-making models (diagnostic and treatment). This situation would give different prevalence, incidence, sensitivities, specificities, predictive values, etc., different depending on the type of doctor-patient relationship and so, finally this has "hidden" epidemiological implications in the morbidity data (prevalence and incidence of diseases and their distribution in the population). Consequently, there is no doubt that the doctor-patient relationship is an aspect of great importance in the treatment of the sick, but also in the epidemiological information.

\section{References}

1. Lilienfeld AM, Lilienfeld DE (1986) Fundamentos de epidemiología. México: Addison-Wesley Iberoamericana.

2. Barker DJP, Rose G (1984) Epidemiology in medical practice. New York: Churchill Livingstone.

3. Harrison C, Henderson J, Miller G, Britt H (2017) The prevalence of diagnosed chronic conditions and multimorbidity in Australia: A method for estimating population prevalence from general practice patient encounter data. 12(3): e0172935.

4. Hernández B, Velasco-Mondragón HE (2000) Encuestas transversales. Salud pública Méx 42(5).

5. Boland M, Sweeney MR, Scallan E, Harrington M, Staines A (2006) Emerging advantages and drawbacks of telephone surveying in public health research in Ireland and the UK. BMC Public Health 6: 208 .

6. Schlundt DG, Hargreaves MK, McClellan L (2006) Geographic clustering of obesity, diabetes, and hypertension in Nashville, Tennessee. J Ambul Care Manage 29(2): 125-132.

7. Boshuizen HC, Poos MJJC, Akker MVD, Boven KV, Korevaar JC, et al. (2017) Estimating incidence and prevalence rates of chronic diseases using disease modeling. Popul Health Metr 15: 13.

8. Turabian JL (1995) Notebooks of Family and Community Medicine. An introduction to the principles of Family Medicine. Madrid: Díaz de Santos. 
9. Turabian JL (2017) Secular Trend throughout 30 Years of Chronic Diseases in a Family Medicine Office in Toledo, Spain: 1985-1995-2016. J Gen Pract (Los Angel) (5): 329.

10. Zellweger U, Bopp M, Holzer BM, Djalali S, Kaplan V (2014) Prevalence of chronic medical conditions in Switzerland: exploring estimates validity by comparing complementary data sources. BMC Public Health 14: 1157.

11. Turabian JL (2017) Prevalence of Chronic Diseases: in Defence of Epidemiological Craftsmanship in Family Medicine. CP Epidemiology 1(1): 005.

12. Schellevis FG, Van de Lisdonk E, Van Der Velden J, Van Eijk JTHM, Van Weel C (1993) Validity of diagnoses of chronic diseases in general practice. The application of diagnostic criteria. J Clin Epidemiol 46: 461-468.

13. Barber J, Muller S, Whitehurst T, Hay E (2010) Measuring morbidity: self-report or health care records?. Fam Prac 27(1): 25-30.

14. Esteban-Vasallo MD, Dominguez-Berjon MF, AstrayMochales J, Genova-Maleras R, Perez-Sania A, et al. (2009) Epidemiological usefulness of populationbased electronic clinical records in primary care: estimation of the prevalence of chronic diseases. Fam Prac 26(6): 445-454.

15. Muggah E, Graves E, Bennett C, Manuel DG (2013) Ascertainment of chronic diseases using population health data: a comparison of health administrative data and patient self-report. BMC Public Health 13: 16.

16. Violan C, Foguet-Boreu Q, Hermosilla-Perez E, Valderas JM, Bolibar B, et al. (2013) Comparison of the information provided by electronic health records data and a population health survey to estimate prevalence of selected health conditions and multimorbidity. BMC Public Health 13: 251.

17. Turabián JL, Pérez Franco B (2012) The symptoms in family medicine are not symptoms of disease, they are symptoms of life. Aten Primaria 44(4): 232-236.

18. Turabian JL (2017) Is The Meaning of Symptoms the Same in Women And Men?. J Women's Health Care (6): 376.

19. Díaz Novás J, Gallego Machado B, León González A (2006) El diagnóstico médico: bases $y$ procedimientos. [The medical diagnosis: bases and procedures]. [Article in Spanish]. Rev Cubana Med Gen Integr 22(1).
20. Turabian JL (2017) For Decision-Making in Family Medicine Context is the Final Arbiter. J Gen Pract (Los Angel) 5: e117.

21. Turabián JL, Pérez Franco B (2010) The diagnostic concept in family medicine: A view of the landscape. Aten Primaria 42(2): 63-128.

22. Turabián JL, Pérez Franco B (2012) Critically examining the symptoms and diagnoses that are taken for granted in family medicine. Creating an own school. Semergen 38(2): 67-71.

23. Turabián JL, Pérez Franco B (2010) The satisfaction adventures with the doctor-patient relationship in the land of questionnaires. Aten Primaria 42(4): 204-205.

24. Laín Entralgo P (1964) La relación médico-enfermo. Historia y teoría. Revista de Occidente, Madrid.

25. Benavides Rodríguez AY (2016) Relación médico paciente desde la percepción de los usuarios y médicos durante la consulta general en el área de consulta externa de la Clínica Médica Previsional, MINSA. Informe final de tesis para optar al título de Máster en Salud Pública. Centro de Investigaciones y Estudios de Salud. Escuela de Salud Pública. Matagalpa, Nicaragua.

26. Frankel RM, Sung SH, Hsu JT (2005) Patients, doctors, and videotape: a prescription for creating optimal healing environments? J Altern Complement Med 11(1): S31-39.

27. Turabián JL, Pérez Franco B (2001) Community Activities in Family Medicine and Primary Care. Madrid: Díaz de Santos.

28. Zoltán Berger F, Alberto Bardi S, Javier Brahm B, Ricardo Latorre M, Eduardo Maiza R, et al. (1991) The physician-patient relationship and the system of health care. Rev méd Chile 127(9).

29. Girón M, Beviá B, Medina E, Simón Talero M (2002) The Quality of the Physician-Patient Relationship and Results of the Clinical Encounters in Primary Care in Alicante: A Focal Groups Study. Rev. Esp. Salud Publica 76(5).

30. Hall JA, Roter DL, Katz NR (1988) Meta-analysis of correlates of provider behavior in medical encounters. Med Care 26(7): 657-675

31. Ong LML, Haes JCJM, Hoos AM, Lammes FB (1995) Doctor-patient communication: a review of the literature. Soc Sci Med (40): 903-918.

32. Weiss LJ, Blustein J (1996) Faithful patients: the effect of long-term physician-patient relationship 


\section{Epidemiology international journal}

on the costs and use of health care by older Americans. Am J Public Health 86(12): 1742-1747.

33. González Menéndez R (1979) Psicología para médicos generales. Ciudad de La Habana, Cuba: Editorial Científico-Técnica.

34. Roter DL, Stewart M, Putnam SM, Lipkin Jr M, Stiles W, Inui TS (1997) Communication patterns of primary care physicians. JAMA 277(4): 350-356.

35. Navathe AS, Clancy C, Glied S (2011) Advancing Research Data Infrastructure for Patient-Centered Outcomes Research. Amol S. Navathe; Carolyn Clancy; Sherry Glied. JAMA 306: 1254-1255.

36. Cuba-Fuentes M, Contreras Samamé JA, Ravello Ríos PS, Castillo Narro MJ, Coayla Flores SA (2016)
Patient-centered medicine as a clinical method. Rev Med Hered (27): 50-59.

37. White P (2005) Biopsychosocial medicine. An integrated approach to understanding illness. New York: Oxford University Press.

38. Anonymous (2018) A simple communication technique to increase patient satisfaction and empowerment. In Practice. A Blog From FPM Journal.

39. Charles C, Gafni A, Whelan T (1999) Decisionmaking in the physician-patient encounter: revisiting the shared treatment decision-making model. Soc Sci Med (49): 651-661. 